\title{
Experimental Study of Heat Transfer to \\ Ceiling from an Impinging Diffusion Flame
}

MATTI A. KOKKALA

VTT-Technical Research Centre of Finland

Fire Technology Laboratory

SF-02150 Espoo, Finland

\begin{abstract}
An experimental study of the heat transfer to a ceiling surface exposed by natural gas flames in the range of $2.9-10.5 \mathrm{~kW}$ is reported. The gas temperature below and the total heat flux to the stagnation point were found to be functions of the ratio of the ceiling and flame height. In the continuous and the intermittent flame regions the stagnation point heat flux was found to be higher than reported earlier by You and Faeth, but to approach their results in the plume region. The heat flux from the ceiling jet to the ceiling agreed well with the earlier results.
\end{abstract}

KEY WORDS: heat transfer, diffusion flames, flame impingement, ceiling jet, experiments

\section{INTRODUCTION}

Inspite of the evident importance, heat transfer from buoyant diffusion flames to a ceiling has been studied relatively little. Most of the related work has dealt with jets of high Reynolds number, which result in such a high heat flux which are never found in connection with impinging flames or plumes of natural fires. Convective heat transfer from impinging plumes has been studied, e.g., by Alpert [1-3], by Zukoski et al. [4,5], and by Cooper et al. [6-9]. In the scale where ignition of combustible linings might be possible the work by You and Faeth [10-13] and that by Heskestad and Hamada [14] are very useful.

The work described in this paper is an experimental study of the heat transfer to a ceiling from impinging buoyant jet flames. The heat flux measurements cover both the stagnation point and the ceiling jet region. The scope of the work is much the same as in the work by You and Faeth [10-13], but our special interest has been on the conditions where ignition of ceiling linings might occur in natural fires. The work has also been documented 
in a technical report, which contains more detailed documentation of the measurements but also results of a study of the ignition of ceiling linings by the impinging flames [15].

\section{EXPERIMENTAL}

A schematic picture of the experimental arrangement is shown in figure 1. A diffusion burner is placed under a circular ceiling plate $1 \mathrm{~m}$ in diameter. A raised floor plate of the same diameter as the ceiling is located $1 \mathrm{~m}$ under the ceiling. The whole apparatus is under a hood which collects all the combustion products. To protect the flames from the draughts in the room the apparatus is surrounded by double screens on all four sides. A third screen is attached to the rods supporting the ceiling in such a way that a $200 \mathrm{~mm}$ open space is left under the ceiling.

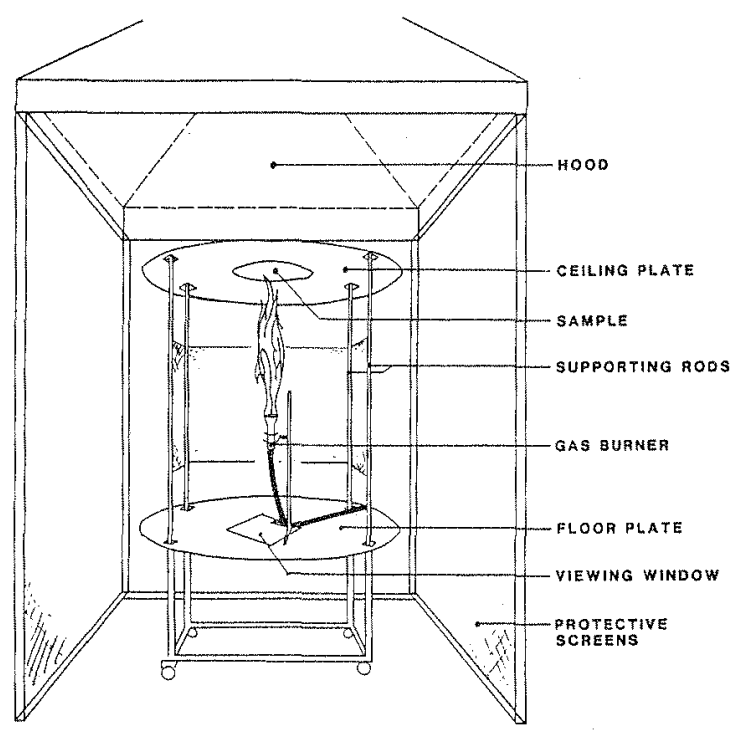

FIGURE 1. Schematic picture of the experimental system.
The burner is a cone filled with $6 \mathrm{~mm}$ glass beads up to about $5 \mathrm{~mm}$ below the $64 \mathrm{~mm}$ diameter upper surface covered with a 16 mesh screen. In all the experiments natural gas containing typically $96 \%$ methane was used as fuel.

The ceiling is made of $12.7 \mathrm{~mm}$ calcium silicate board. The central portion of $0.305 \mathrm{~mm}$ diameter is removable to make the change of the instrumentation easy. A close-up of the centre of the ceiling is shown in figure 2 . The centre plate (or the sample in the subsequent ignition studies) is attached with steel bolts to a $0.4 \mathrm{~m}$ diameter back-board of the same thickness. In some experiments a third calcium silicate plate was added to increase the thermal thickness of the ceiling.

\section{FLAME SHAPES}

The size and shape of the visible flames offer a convenient way to compare flames of different experiments. In this work the flame shapes were recorded on video. Against a dark background the boundaries of the luminous flame were well defined within the time resolution of the individual frames, i.e., 1/30 s. 


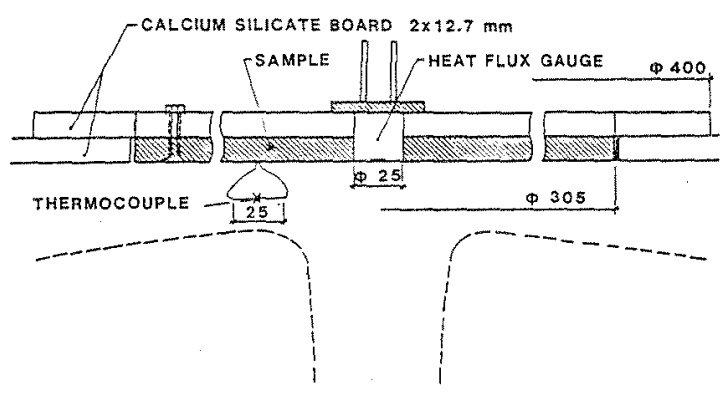

FIGURE 2. Close-up of the ceiling (not to scale). In typical experiments total heat flux gauges and $75 \mu \mathrm{m}$ bare thermocouples were used.

The height of the free flames was determined using the intermittency definition of Zukoski et al. [5]. The intermittency $I$ is the fraction of time during which at least part of the luminous flame lies above a horizontal plane located at elevation $\mathrm{Z}$ above the burner. The average flame length $\mathrm{H}_{\mathrm{f}}$ is defined as the height $\mathrm{Z}$ at which $\mathrm{I}=0.5$, i.e., half of the time the flame tip is below the level $\mathrm{H}_{\mathrm{f}}$ and half of the time above that.

Figure 3 shows the measured free flame heights as a function of a dimensionless heat release rate [5]

$Q_{D}^{*}=Q /\left(c_{p} T_{\infty} P_{\infty} g^{1 / 2} D^{5 / 2}\right)$

where $c_{p}$ is the specific heat and $\rho_{\infty}$ the density of air at ambient temperature $T_{\infty}, g$ the acceleration of gravity, and $Q$ the total heat release rate. The intermittent flame region of our flames is shown by the vertical bars. Our flames are about $20 \%$ higher than those of

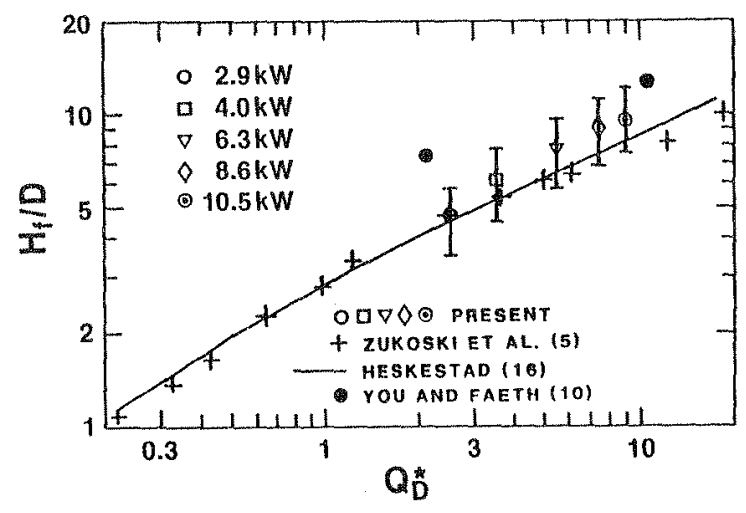

FIGURE 3. Dimensionless free flame height $H_{f} / D$ as a function of the dimensionless heat release rate $Q^{*}$. 
Zukoski et al. [5] or Heskestad [16], but the two flames of You and Faeth are much longer. The difference may be partly due to the different burners, but also due to the different methods of determining the free flame length. A great amount of comparable experimental results are available. The early data have been reviewed, e.g., by You and Faeth [11]. To prevent the figure from getting overloaded with data points, only the data from the experiments with methane or natural gas have been included.

When the flames impinged on the ceiling, we found that the average ceiling flame radius $H_{R}$ determined by the intermittency principle can be expressed as $H_{R}=\left(H_{f}-H\right) / 2$, i.e., the sum of the ceiling height $\mathrm{H}$ (the distance between the upper surface of the burner and the lower surface of the ceiling) and the ceiling flame diameter $2 \mathrm{H}_{\mathrm{R}}$ equals the free flame height $\mathrm{H}_{\mathrm{f}}$ [15]. This correlation is very close to that given by You and Faeth [11].

\section{TEMPERATURE DISTRIBUTION}

The temperatures in the ceiling jet were measured with $\mathrm{K}$-type thermocouples made of $75 \mu \mathrm{m}$ wire. Inside the flame thermocouples made of $250 \mu \mathrm{m}$ wire were used.

The gas temperature at the stagnation point under the ceiling is shown in figure 4 . The dimensionless temperature rise $\Delta T / T_{\infty}$ is presented as a function of $H / \mathrm{Q}^{*}{ }_{\mathrm{D}}^{2 / 5}$. The continuous lines represent the correlations given by McCaffrey for a free pool fire [17]. In the plume region we have too few points to allow a sound comparison of the dependencies on $\mathrm{Q}$ and $\mathrm{H}$. In the intermittent flame region our data suggests a steeper decrease of temperature with height than in [17]. The difference from McCaffrey's flames is further shown by the considerably higher temperature in the continuous flame region. Only for the smallest

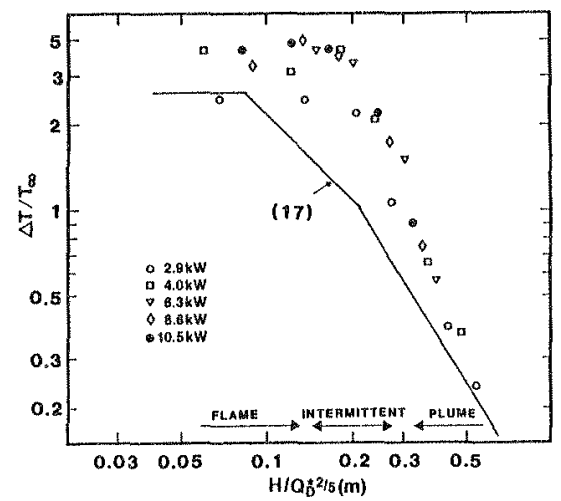

FIGURE 4. Relative temperature rise in the gas $18 \mathrm{~mm}$ beneath the stagnation point as a function of the ratio of the ceiling height $\mathrm{H}$ to the dimensionless heat release rate $\mathrm{Q}_{\mathrm{D}}^{*} 2 / 5$.

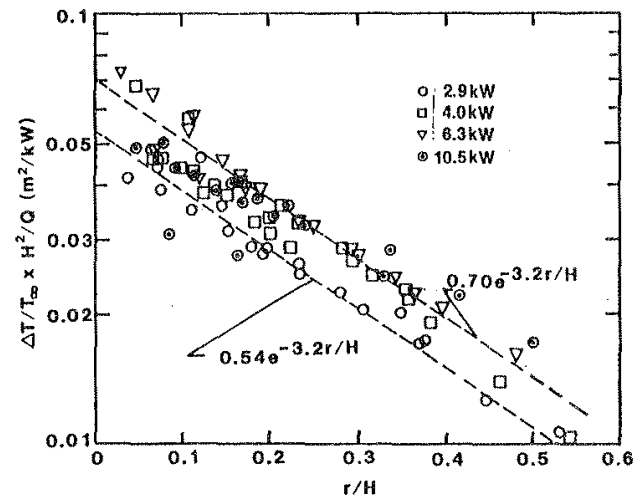

FIGURE 5. Relative rise of gas temperature in the ceiling jet $18 \mathrm{~mm}$ beneath the ceiling divided by the scaled heat release rate $\mathrm{Q} / \mathrm{H}^{2}$ as a function of the dimensionless radial distance $\mathrm{r} / \mathrm{H}$. 
flame of $2.9 \mathrm{~kW}$ the temperature rise is about the same as for McCaffrey's buoyant flame. The differences are qualitatively as expected, because our flames are not "purely byoant". Due to the higher $Q_{D}^{*}$ the flames have some jet-like characteristics.

Figure 5 shows the dimensionless temperature rise as a function of the dimensionless radial distance $\mathrm{r} / \mathrm{H}$. The thermocouples measuring the temperature of the ceiling jet are located $18 \mathrm{~mm}$ below the ceiling surface. The constant spacing unfortunately means that thermocouples are not recording the maximum temperature of the ceiling jet.

Because different flame regimes (flame, intermittent, plume) are impinging the ceiling, evidently no single function exists, which is sufficient to correlate all the experimental data. In figure 5, however, an attempt is made. We have made a simple scaling by assuming that $\Delta \mathrm{T} / \mathrm{T}=\mathrm{QH}^{-2} \mathrm{f}(\mathrm{r} / \mathrm{H})$ where $\mathrm{f}(\mathrm{r} / \mathrm{H})$ is an empirical function. With the exception of the biggest $10.5 \mathrm{~kW}$ flame, the temperature rise appears to fall exponentially as a function of $\mathrm{r} / \mathrm{H}$. In the range $0.1<\mathrm{r} / \mathrm{H}<0.5$ we suggest an empirical correlation $\Delta \mathrm{T} / \mathrm{T}=\mathrm{QH}^{-2} \cdot \mathrm{K}_{\mathrm{e}} \exp (-3.2 \mathrm{r} / \mathrm{H})$. A graphical fit results in $\mathrm{K}_{\mathrm{e}}=0.70$ for $4.0 \mathrm{~kW}<\mathrm{Q}<8.4 \mathrm{~kW}$ and $\mathrm{K}_{\mathrm{e}}=0.54$ for $\mathrm{Q}=2.9 \mathrm{~kW}$.

\section{HEAT FLUX TO THE CEILING}

In the heat flux measurements both Gardon and Schmidt-Boelter type (Medtherm) total heat flux gauges mounted as shown in figure 2 were used to provide material independent data on the input flux. The results of measurements for the stagnation point are shown in figure 6 as a function of the ratio of the ceiling height and the free flame height $\mathrm{H} / \mathrm{H}_{\mathrm{f}}$. The maximum flux is about $60 \mathrm{~kW} / \mathrm{m}^{2}$, and it appears in the regime $1.5<\mathrm{H}_{\mathrm{f}} / \mathrm{H}<3.5$ for the whole heat release range.

You and Faeth [11] derived a correlation model for the stagnation point heat flux. By fitting to experimental results they obtained

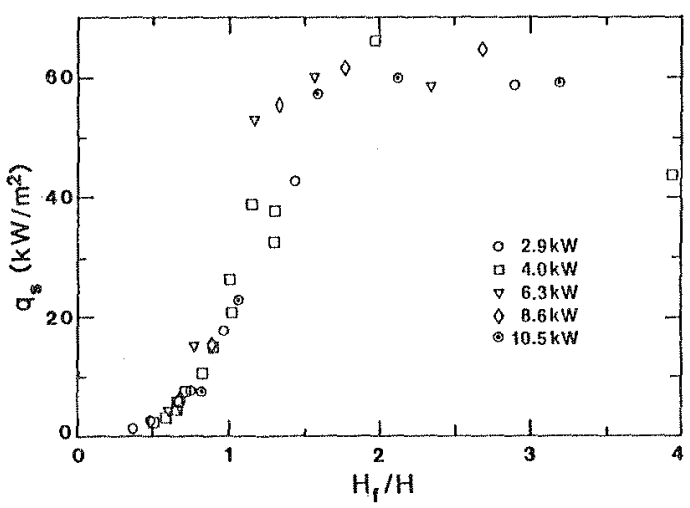

FIGURE 6. Total heat flux to the stagnation point as a function of the ratio of the flame height $\mathrm{H}_{\mathrm{f}}$ and the ceiling height $\mathrm{H}$. 


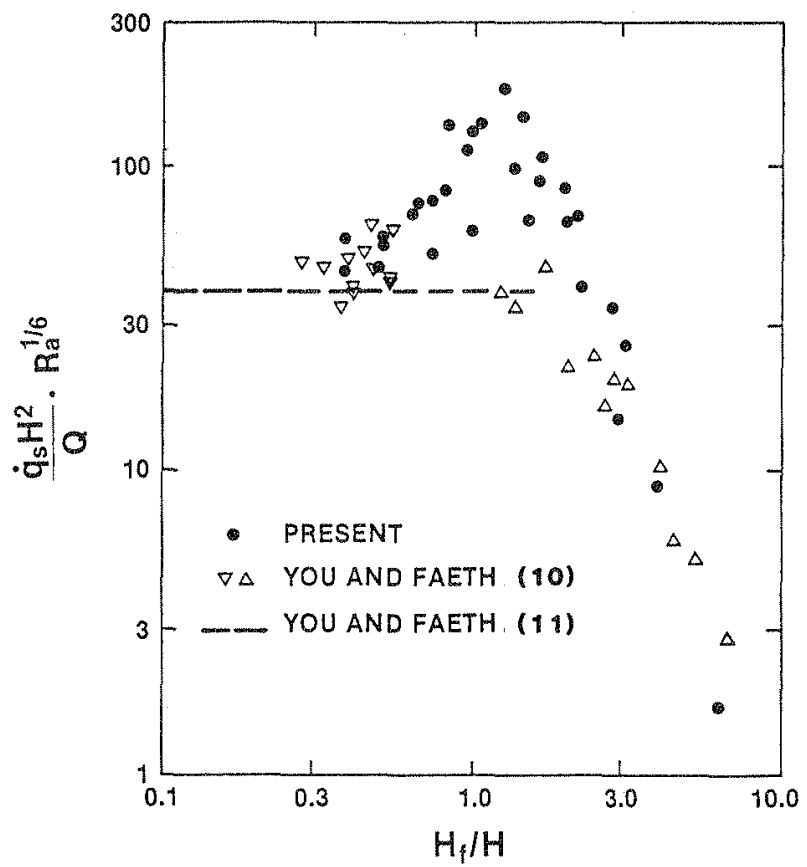

FIGURE 7. Dimensionless total stagnation point heat flux as a function of the ratio of the flame height and the ceiling height.

$\mathrm{q}_{\mathrm{S}}\left(\mathrm{H}^{2} / \mathrm{Q}\right) \cdot \mathrm{Ra}^{1 / 6} \cdot \operatorname{Pr}^{3 / 5}=31.2$

where the Rayleigh number $\mathrm{Ra}=\mathrm{g} \beta Q \mathrm{H}^{2} / \rho c_{\mathrm{p}} \mathrm{v}^{3}$ and the Prandtl number $\operatorname{Pr}=\mu \mathrm{c}_{\mathrm{p}} / \mathrm{k}$ and where $\mu$ is the dynamic and $v$ the kinematic viscosity, $k$ the thermal conductivity and $\beta$ the thermal expansion coefficient of the gas. The fit has been reported to be valid for $\mathrm{H}_{\mathrm{f}} / \mathrm{H}<1.5$. The present results are compared to those of You and Faeth in figure 7. For small or large $\mathrm{H}_{\mathrm{f}} / \mathrm{H}$ the data agree. In the range $0.7<\mathrm{H}_{\mathrm{f}} / \mathrm{H}<2$ our data points are remarkably higher. In that region the surface of the gauge was getting sooty during the experiment, which may have had an effect on the measured flux values. However, no systematic drift of the signal was observed.

The convective fraction of the total heat flux was measured with a gold-foil gauge with an emissivity of about 0.1 . Depending on the conditions more or less sooting of the gauge took place, but no systematic drift of the flux reading was observed. Inside the flame the radiative fraction was typically $40 \%$. The maximum radiative fraction of $50-60 \%$ was found close to the average flame height, and above the flame the radiative fraction decreased rapidly. These values appear high for a natural gas flame. However, the flames are very sooty because of the quenching effect of the ceiling. Therefore, a higher radiative fraction than estimated from the free flame absorption coefficient can be expected. 


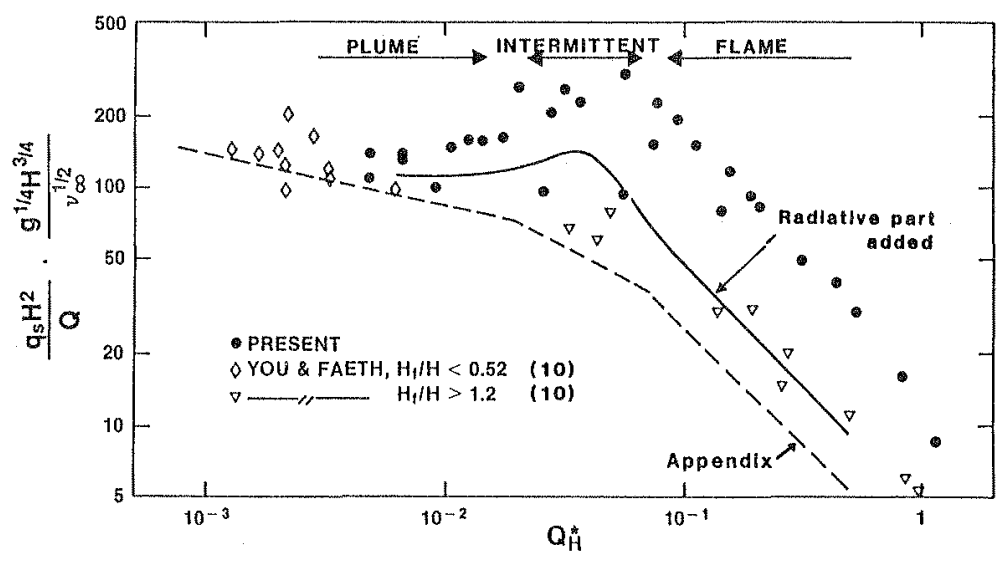

FIGURE 8. Dimensionless scaled heat flux as a function of the dimensionless heat release rate. The dashed line is the estimate of the convective heat flux derived in the Appendix. The continuous line is the estimate of the total flux obtained by multiplying the estimated convective flux by the measured ratio of the total and the convective fluxes.

Equation (2) was derived using the flow and temperature relations of the far plume region. In the Appendix the same procedure is applied to derive the expressions for the intermittent and continuous flame regions. The result is shown by the dashed line in figure 8 , where $\mathrm{Q}_{\mathrm{H}}^{*}$ is obtained from Equation (1) by replacing $\mathrm{D}$ by $\mathrm{H}$. The curious way of making the heat flux dimensionless is chosen in order to make the theoretical estimate of the convective flux to fall on a single line in the plume region. In figure 8 the continuous line presents a very rough estimate of the total heat flux because the radiative part of the flux is not a function of $Q_{D}^{*}$ only.

Our data approaches the theoretical line for the far plume region ( $\operatorname{small} \mathrm{Q}_{\mathrm{H}}{ }^{*}$ ). In the intermittent and flame regions the data points are five to six times higher than the estimated convective flux. The radiative component alone does not explain the difference. Other mechanisms, such as in-phase fluctuations of velocity and temperature or combustion reactions close to the gauge surface, may enhance the convective flux. In general, we do not even expect that our results would agree too well with the estimate based on McCaffrey's correlations, because our flames have substantial jet-like features. McCaffrey's correlations are, however, the most detailed of that kind available and they do, therefore, serve as a good reference for studying various fire problems.

Alpert has derived a model to calculate the temperature and the velocity in the ceiling jet $[1,2]$. The model can be used to estimate the convective heat flux to the ceiling. Alpert's model is compared to the measurements in figure 9 . With a friction factor $\mathrm{f}$ in the range of $0.02-0.03$ the model gives a reasonable estimate, but there are evidently some systematic deviations in the data. The earlier data for other fuels than natural gas published by You and Faeth [11] and Alpert [1,2] fall well among our data. Their data is not, however, presented here to keep the figure more readable. 


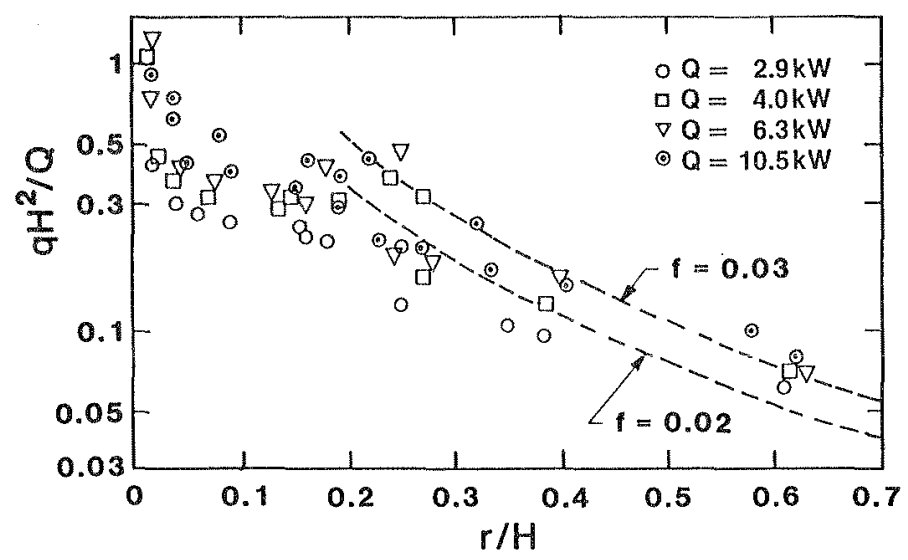

FIGURE 9. Dimensionless heat flux $\mathrm{qH}^{2} / \mathrm{Q}$ as a function of the dimensionless radial distance $\mathrm{r} / \mathrm{H}$. The dashed lines are calculated using a model presented by Alpert $[1,2]$.

\section{CONCLUSIONS}

In this work results from flame length, temperature and heat flux measurements for impinging buoyant jet diffusion flames have been reported. The flame height scale $\mathrm{H}_{\mathrm{f}} / \mathrm{H}$ was found to be the most succesful way to correlate the gas temperature below and the heat flux to the stagnation point.

In the continuous and in the intermittent flame regions the heat flux to the stagnation point is considerably higher than given by the measurements of You and Faeth [11], but in the plume region $\mathrm{H}_{\mathrm{f}} / \mathrm{H}<0.5$ the agreement is reasonable. No satisfactory quantitative explanation for the difference of the results has been found. Such an explanation is definitely needed as the differences are biggest for the conditions under which ignition of ceiling surface may occur in natural fires.

\section{APPENDIX: ESTIMATION OF THE CONVECTIVE HEAT FLUX TO THE STAGNATION POINT} plume,

Sibulkin [18] proposed an expression for the stagnation point heat flux $q_{S}$ of a jet or a

$\mathrm{q}_{\mathrm{S}} \propto \operatorname{Pr}^{-3 / 5} \mathrm{v}^{1 / 2} \mathrm{c}_{\mathrm{p}} \rho\left(\mathrm{T}-\mathrm{T}_{\mathrm{w}}\right)\left[(\mathrm{dv} / \mathrm{dr})_{\mid \mathrm{r}=0}\right]^{1 / 2}$

where Pr is the Prandtl number, $v$ the kinematic viscosity, $\rho$ the density, $c_{p}$ the specific heat capacity, and $\mathrm{T}$ the temperature at the location of the stagnation point without the presence of the ceiling at temperature $T_{w}$. The velocity gradient $d v / d r$ is calculated at the axis, i.e., at $\mathrm{r}=0$. Donaldson et al. [19] obtained an expression for the velocity gradient at $\mathrm{r}=0$,

$\mathrm{dv} / \mathrm{dr} \propto \mathrm{V}_{\mathrm{c}} / \mathrm{r}_{1 / \mathrm{e}}$ 
where $V_{c}$ is the flow velocity along the axis of the jet and $r_{1 / \mathrm{e}}$ the width of the jet at the location of the stagnation point without the presence of the ceiling. Because the product of the terms in Eq. (A.1) containing $\operatorname{Pr}, \rho, v$, and $c_{p}$ is almost independent of temperature, we get:

$\mathrm{q}_{\mathrm{S}} \infty \Delta \mathrm{T}\left[\mathrm{V}_{\mathrm{c}} / \mathrm{r}_{1 / \mathrm{e}}\right]$,

where $\Delta \mathrm{T}=\mathrm{T}-\mathrm{T}_{\mathrm{W}}$

We take the dimensional expressions from [17] with the following units $[\Delta \mathrm{T}]={ }^{\circ} \mathrm{C}$, $\left[\mathrm{V}_{\mathrm{c}]}=\mathrm{m} / \mathrm{s},\left[\mathrm{r}_{1 / \mathrm{e}}\right]=[\mathrm{H}]=\mathrm{m}\right.$, and $[\mathrm{Q}]=\mathrm{kW}$ :

plume:

$$
\begin{aligned}
\Delta \mathrm{T} & =21.6 \mathrm{H}^{-5 / 3} \mathrm{Q}^{2 / 3} \\
\mathrm{~V}_{\mathrm{c}} & =1.12 \mathrm{H}^{-1 / 3} \mathrm{Q}^{1 / 3} \\
\mathrm{r}_{1 / \mathrm{e}} & =0.192 \mathrm{H},
\end{aligned}
$$

intermittent: $\quad \Delta \mathrm{T}=62.9 \mathrm{H}^{-1} \mathrm{Q}^{2 / 5}$

$$
\begin{aligned}
& \mathrm{V}_{\mathrm{c}}=1.93 \mathrm{Q}^{1 / 5} \\
& \mathrm{r}_{1 / \mathrm{e}}=0.46 \mathrm{H} \mathrm{Q}^{-2 / 5}+0.013 \mathrm{Q}^{1 / 2}
\end{aligned}
$$

flame:

$$
\begin{aligned}
& \Delta \mathrm{T}=\text { constant }=\left(797^{\circ} \mathrm{C}\right) \\
& \mathrm{V}_{\mathrm{c}}=6.84 \mathrm{H}^{1 / 2} \\
& \mathrm{r}_{1 / \mathrm{e}}=0.46 \mathrm{H} \mathrm{Q}^{-2 / 5}+0.013 \mathrm{Q}^{1 / 2}
\end{aligned}
$$

By applying the above expressions to Eq. (A.3), we get for

plume:

$$
\begin{aligned}
& \mathrm{q}_{\mathrm{s}} \propto \mathrm{Q}^{5 / 6} \mathrm{H}^{-7 / 3} \\
& \mathrm{q}_{\mathrm{S}} \mathrm{H}^{11 / 4} / \mathrm{Q} \propto \mathrm{Q}^{-1 / 6} \mathrm{H}^{5 / 12} \propto \mathrm{Q}_{\mathrm{H}}^{*-1 / 6},
\end{aligned}
$$

intermittent: $\quad \mathrm{q}_{\mathrm{s}} \propto \mathrm{Q}^{1 / 2} \mathrm{H}^{-1} / \mathrm{f}(\mathrm{Q}, \mathrm{H})$

$$
\begin{aligned}
& \mathrm{q}_{\mathrm{S}} \propto \mathrm{Q}^{1 / 2} \mathrm{H}^{-1} / \mathrm{f}(\mathrm{Q}, \mathrm{H}) \\
& \mathrm{q}_{\mathrm{S}} \mathrm{H}^{11 / 4} / \mathrm{Q} \propto \mathrm{Q}^{-1 / 2} \mathrm{H}^{7 / 4} / \mathrm{f}(\mathrm{Q}, \mathrm{H}) \propto \mathrm{Q}^{*}{ }_{\mathrm{H}}^{-0.6},
\end{aligned}
$$

flame:

$$
\begin{aligned}
& \mathrm{q}_{\mathrm{S}} \propto \mathrm{H}^{1 / 4} / \mathrm{f}(\mathrm{Q}, \mathrm{H}) \\
& \mathrm{q}_{\mathrm{S}} \mathrm{H}^{11 / 4} / \mathrm{Q} \propto \mathrm{H}^{3} \mathrm{Q}^{-1} / \mathrm{f}(\mathrm{Q}, \mathrm{H}) \propto \mathrm{Q}_{\mathrm{H}}^{*}{ }^{-1.1},
\end{aligned}
$$

where

$$
f(Q, H)=\left[\mathrm{H} \mathrm{Q}^{-2 / 5}+0.0283 \mathrm{Q}^{1 / 2}\right]^{1 / 2} \text {. }
$$

Inspite of the difference compared to the results of McCaffrey [17] we have assumed that the intersection of the plume and the intermittent region for the flames of this work occurs approximately at $\mathrm{Q}_{\mathrm{H}}^{*}=0.019$ and the intersection of the intermittent and the continuous flame regions approximately at $\mathrm{Q}_{\mathrm{H}}{ }_{\mathrm{H}}=0.06$.

\section{ACKNOWLEDGEMENT}

The experiments were carried out at the Center for Fire Research of the NBS (now NIST). The author wishes to gratefully acknowledge Dr. James Quintiere for advice 
throughout the work and Mr. Bill Rinkinen for assistance in constructing the experimental system and in running the tests.

\section{REFERENCES}

1. Alpert, R.L., "Fire induced turbulent ceiling-jet", FMRC Serial No. 19722-2, Norwood, MA, 91 p., 1971.

2. Alpert, R.L., "Turbulent ceiling-jet induced by large scale fire", Combust. Sci. Tech., 11, pp. 197-213, 1975 .

3. Alpert, R.L., "Convective heat transfer in the impingement region of a buoyant plume", ASME J. Heat Transfer, 109: 1, pp. 120-124, 1987.

4. Zukoski, E.E. and Kubota, T., "An experimental investigation of the heat transfer from a buoyant gas plume to a horizontal ceiling - Part 2", NBS-GCR-77-98, Gaithersburg, MD, 78 p., 1977.

5. Zukoski, E.E., Kubota, T. and Cetegen, B., "Entrainment in fire plumes", Fire Safety Journal, 3 , pp. 107-121, 1980/81.

6. Cooper, L.Y., "Heat transfer from a buoyant plume to an unconfined ceiling", $\underline{\text { J. Heat }}$ Transfer, 104 , pp. 446-451, 1982.

7. Cooper, L.Y., "Thermal response of unconfined ceilings above growing fires and the importance of convective heat transfer", 22nd National Heat Transfer Conference, Paper 84-HT-105, 9 p., 1984.

8. Cooper, L.Y. and Stroup, D.W., "Thermal response of unconfined ceilings above growing fires and the importance of convective heat transfer", ASME J. Heat Transfer, 109: 1, pp. 172-178, 1987.

9. Cooper, L.Y. and Woodhouse, A. "The buoyant plume-driven adiabatic ceiling temperature revisited", Journal of Heat Transfer, 108, pp. 822-826, 1986.

10. You, H.Z and Faeth, G.M. "An investigation of fire impingement on a horizontal ceiling", Report prepared for the NBS, 95 p., 1978.

11. You, H.Z. and Faeth, G.M. "Ceiling heat transfer during fire plume and fire impingement", Fire and Materials, 3: 3, pp. 140-147, 1979.

12. You, H.Z and Faeth, G.M., "An investigation of fire impingement on a horizontal ceiling", Report prepared for the NBS, 38 p., 1979.

13. You, H.Z. and Faeth, G.M., "An investigation of fire impingement on a horizontal ceiling", NBS-GCR-81-304, Gaithersburg, MD, 83 p., 1981.

14. Heskestad, G. and Hamada, T., "Ceiling flows of strong fire plumes", FMRC J.I. OKOE1.RU, Norwood, MA, 43 p., 1984.

15. Kokkala, M.A., "Heat transfer to and ignition of ceiling by an impinging diffusion flames", VTT Research Reports 586, Espoo, 70 p. + app. 6 p., 1989.

16. Heskestad, G. "Luminous heights of turbulent diffusion flames", Fire Safety Journal, 5, pp. 103-108, 1983.

17. McCaffrey, B.J., "Purely buoyant diffusion flames: some experimental results", NBSIR 79-1910, Gaithersburg, MD, 49 p., 1979.

18. Sibulkin, M. "Heat transfer near the forward stagnation point of a body of revolution", J. Aeron. Sci., 25, pp. 73-86, 1958.

19. Donaldson, C. duP., Snedeker, R.S., and Margolis, D.P., "A study of free jet impingement. Part 2.", Journal of Fluid Mechanics, 45, pp. 477-512, 1971. 